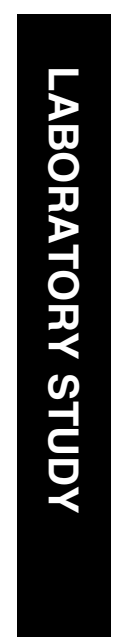

\title{
Expression of the PDE5 enzyme on human retinal tissue: new aspects of PDE5 inhibitors ocular side effects
}

'Department of Histology, Microbiology and Medical Biotechnologies, University of Padova, Padova, Italy

${ }^{2}$ Department of Pathology, S Bassano Hospital, Bassano, Italy

${ }^{3}$ Department of Ophthalmology, S Antonio Hospital, Padova, Italy

Correspondence: C Foresta, Clinical Pathology Chair, University of Padova, Department of Histology, Microbiology and Medical Biotechnologies, Centre for Male Gamete Cryopreservation,

Via Modena 9, Padova 35128, Italy

Tel: 39049 8218517; Fax: 390498218520

E-mail: carlo.foresta@ unipd.it

Received: 18 December 2006

Accepted in revised form: 25 May 2007

Published online: 22 June 2007

Grant: none
Abstract

Objective We tested the effect of two phosphodiesterase type-5 (PDE5) inhibitors, sildenafil and tadalafil, on ophthalmic artery (OA) blood flow velocity and investigated the presence of the PDE5 enzyme on human retinal tissue in comparison with the PDE6 enzyme localization.

Methods Using Colour Doppler ultrasonography (CDU) we investigated, in 30 healthy young subjects (27.8 years of age; range, 24.3-33.7 years), the effects of a single oral dose of sildenafil $(100 \mathrm{mg})$, tadalafil (20 mg), and placebo on OA blood flow velocity. Western blot for PDE6 and PDE5 protein expression was performed on frozen samples of human retina, testis, sperm, skin, and corpus cavernosum.

Immunohistochemistry was performed on two ocular globes from dead donors.

Results CDU showed a relationship between the administration of PDE5 inhibitors and OA blood flow velocity modifications in a timedependent manner. Western blot and immunohistochemical analysis showed PDE6 and PDE5 presence in human retinal tissue and gave a map of its distribution.

Conclusion We demonstrated that (a) tadalafil and sildenafil are able to modify the OA flux in a time-dependent manner; (b) the PDE5 enzyme is expressed on retinal and choroid vasculature (smooth muscle and endothelial cells), on ganglion and bipolar cells; (c) human retinal tissues express the PDE6 enzyme in the rod and cone photoreceptors; (d) visual side effects after PDE5 inhibitors administration may be linked to a specific effect on the PDE5 enzyme; and (e) the PDE5 enzyme may have a physiologic role on ganglion and bipolar cells that need to be further investigated.
C Foresta', N Caretta', D Zuccarello', A Poletti ${ }^{2}$, A Biagioli', L Caretti ${ }^{3}$ and A Galan ${ }^{3}$
Eye (2008) 22, 144-149; doi:10.1038/sj.eye.6702908; published online 22 June 2007

Keywords: cyclic GMP; immunohistochemistry; phosphodiesterase; blood flow; retinal cells

\section{Introduction}

Phosphodiesterase type-5 (PDE5) inhibitors are a widely used class of drugs initially studied for their potential effect on the cardiovascular system. It soon became evident that PDE5 inhibitors have considerable effects on the biochemical signalling pathway leading to erection. Since this discovery, the use of PDE5 inhibitors in the treatment of erectile dysfunction (ED) is now considered a cornerstone. ${ }^{1-4}$ Administration of PDE5 inhibitors has been associated with visual disturbances such as blue tinge, increased brightness of lights and blurred vision; ${ }^{5}$ however, the exact mechanism of these disturbances has not been definitively elucidated. We set out to study the effect of sildenafil and tadalafil on ophthalmic artery (OA) blood flow velocity. Furthermore, we investigated the expression of the PDE5 enzyme on human retinal tissue in comparison with the PDE6 enzyme localization.

Patients and methods

The research followed the tenets of the Declaration of Helsinki. After approval by Local Ethics Committee of the University of Padova, 30 healthy young subjects (27.8 years of age; range, $24.3-33.7$ years) gave informed consent and were enrolled in this study (double-blind and placebo-controlled) to investigate the effects 
of a single oral dose of sildenafil $(100 \mathrm{mg})$, tadalafil (20 mg), and placebo on OA blood flow velocity by using Colour Doppler ultrasonography (CDU). Subjects were randomly and blindly assigned to each group. Patients with coronary artery disease, diabetes mellitus, systemic hypertension, and ocular diseases were excluded from the study. All subjects underwent an ophthalmologist's clinical and instrumental examination to exclude degenerative or vascular ocular diseases. Intraocular pressure was below $21 \mathrm{mmHg}$ in both eyes and none of the patients was under any continuous and ophthalmological medication or any treatment with nitrates. Systolic and diastolic blood pressure were measured before and $1 \mathrm{~h}$ after the dose of PDE5 inhibitor or placebo. The patients were also questioned about side effects and visual symptoms. For evaluation of ocular blood flow, CDU measurements were performed using a high-resolution Echo-Colour-Doppler (AU5, Esaote, Genoa, Italy) equipped with a $7.5 \mathrm{MHz}$ linear probe with $<0.2 \mathrm{~mm}$ axial resolution. After administration of a single tablet of sildenafil, tadalafil, or placebo, the OA was examined as follows. After $15 \mathrm{~min}$ rest in supine position in a quiet and semi-darkened room, ultrasound gel was applied to the closed eyelid of the orbits; Doppler probe was then placed and moved gently on the eyelid to avoid any pressure on the eye. The peak systolic velocity (PSV) and end-diastolic velocity (EDV) were measured on the $\mathrm{OA}^{6-8}$ in both orbits. Doppler examination was performed in each subject at baseline and after 1, 4, 12, 24,36 , and $48 \mathrm{~h}$ after the drug administration to evaluate the influence of PDE5 inhibitors at different circulating concentration. Immunoblotting assay and immunohistochemistry were performed on two ocular globes from different donors following cornea removal for transplantation. These two Caucasian donors, aged 45 and 51 respectively, were healthy and without ocular disease.

For immunoblotting assay, a total cellular proteins extract has been obtained by frozen samples of human retina, testis, sperm, skin, and corpus cavernosum, using the standard protocol of ReadyPrep Protein Extraction Kit (Biorad, Hercules, CA, USA). The final concentration of proteins has been determined by Bradford proteins assay. Primarily, the compatibility and functionality of primary (anti-PDE5 and anti-PDE6) and secondary (anti-rabbit) antibodies has been tested by dot-blot assay. Aliquots of the samples, containing equal amounts of proteins $(20 \mu \mathrm{g})$, were suspended in reducing SDS-PAGE sample buffer and boiled for $5 \mathrm{~min}$. Proteins were separated by $10 \%$ SDS-PAGE and transferred to polyvinylidene difluoride membranes using the Minitransblot system (both Biorad, Hercules, CA, USA). These membranes were incubated in blocking buffer (0.05\% Tween-20 in phosphate-buffered saline (PBS) containing $0.5 \%$ casein) for 1 hour, followed by overnight incubation with primary rabbit antibodies directed against PDE5 and PDE6 at $4^{\circ} \mathrm{C}$ (Abcam, Cambridge, UK). After incubation with a secondary horseradish peroxidase (HRP)-conjugated goat anti-rabbit polyclonal antibody (BD Transduction Laboratories, Franklin Lake, NJ, USA), immunoreactivity was detected by chemiluminescence (ECL) detection system (Amersham Pharmacia Biotech, Uppsala, Sweden) (Figure 2a and b).

For immunohistochemistry, tissue was formalin-fixed and processed into paraffin wax using standard methods. Sections ( $3 \mu \mathrm{m})$ were cut, mounted onto polylisinated slides, dried at $40^{\circ} \mathrm{ON}$, dewaxed, rehydrated in graded ethanols. Endogenous peroxidase was blocked with $0.3 \%$ hydrogen peroxide containing sodium azide and levamisol for $6 \mathrm{~min}$ and then rinsed gently in PBS for $3 \mathrm{~min}$. For the staining we used the Envision + Dual Link System-HRP (DAB +)

(DakoCytomation, Fort Collins, CO, USA) that is based on an HRP-labeled polymer which is conjugated with secondary antibodies, this system does not require Normal Goat Serum incubation for nonspecific binding. The primary antibody was serial diluted $(1: 400,1: 800$, and $1: 1600$ ) and incubated for $30 \mathrm{~min}$ at room temperature, then slides were washed in PBS for $3 \mathrm{~min}$ and stained with the peroxidase-labeled polymer for $30 \mathrm{~min}$. After a wash in PBS the substrate-chromogen solution was applied and incubated for $5 \mathrm{~min}$. At the end, slices were washed with distilled water and counterstained with hematoxilin. The primary antibody against PDE-6 enzyme was provided by Abcam (Cambridge, CA, UK). It was a polyclonal $\mathrm{Ab}$ raised in rabbit and immunogen affinity purified. The Abcam's synthetic peptide is 'MGEVTAEEVEKFLDSN', corresponding to amino acids 1-16 of human PDE6 $\alpha$. This sequence is completely conserved in humans, mouse, and bovine and $94 \%$ conserved in canine. The primary antibody against PDE- 5 was provided by Abcam (Cambridge, CA, UK). It was a polyclonal Ab raised in rabbit and immunogen affinity purified. Abcam's immunogen is a synthetic cyclic peptide (common to all PDE5A variants). Data are expressed as median (range). Comparison between baseline and at each end point was performed by the Wilcoxon sum ranks test for matched pairs. $P$-values $<0.05$ were regarded as statistically significant.

\section{Results}

No statistically significant differences in heart rate, systolic, and diastolic blood pressure were found between the values before and $1 \mathrm{~h}$ after drugs (sildenafil, tadalafil, and placebo) administration $(P>0.05)$. Functional studies on the PDE5 inhibitors and placebo influence on OA blood flow velocity are given in Table 1 
and Figure 1. Measurements were done at each end point (baseline, 1, 4, 8, 12, 24, 36, and 48 h) for the three drugs (sildenafil, tadalafil, and placebo). Colour Doppler measurements of the right and left eyes were compared using the Mann-Whitney $U$-test before and after drug intake. No statistical differences was detected between the right and left eyes $(P>0.05)$. Administration of $100 \mathrm{mg}$ sildenafil resulted in a significant increase $(P<0.01)$ in OA PSV and EDV at $60 \mathrm{~min}$ after drug uptake. At 4, 8, 12, 24, 36, and $48 \mathrm{~h}$ after sildenafil uptake OA blood flow velocity values no longer differed significantly from baseline (Table 1 and Figure 1). Tadalafil $(20 \mathrm{mg})$ administration determined a significant increase $(P<0.001$ and $P<0.01)$ in OA PSV and EDV values at $1,4,8,12,24$, and $36 \mathrm{~h}$ after uptake (Table 1 and Figure 1). Placebo administration have no influence on OA blood flow velocity values (Table 1 and Figure 1). After PDE5 inhibitors administration, no cardiovascular events were found and side-effect rates were similar to those reported in literature: six patients (20\%) reported side effects like headache (three patients), nasal congestion (one patient), flushing (one patient), and increased light sensitivity (one patient). Other visual side effects were not reported. To evaluate the possible direct influence of PDE5 inhibitors on retinal blood flow and function we performed an immunoblotting assay and an immunohistochemistry on retinal tissue for PDE5 and PDE6 expression.

Figure 2 provides Western blot for PDE6 and PDE5 protein expression ( $a$ and $b$ ) and immunohistochemistry for both enzymes (c and d). Western blot for both PDE5 and PDE6 demonstrate the presence of the two proteins in retinal tissues. The immunohistochemical analysis clearly revealed that the PDE6 enzyme is expressed on the photoreceptor layer both on rods and cones. Finally, we demonstrated the PDE5 localization on endothelial and smooth muscle cells of the vascular wall (retina and choroids vessels), on ganglion (III neuron), and bipolar cells (II neuron).

\section{Discussion}

Selective PDE5 inhibitors are widely used drugs for the treatment of ED, given that PDE5 is thought to be responsible of penis detumescence. Inhibition of PDE5 is known to increase the level of cyclic guanosine monophosphate (cGMP), an intracellular messenger effecting vasodilation by relaxation of smooth muscle in arterioles. Production of cGMP from guanosine triphosphate is mediated through the nitric oxide (NO) signalling pathway. By inhibiting PDE5, PDE5 inhibitors increase cGMP levels and thereby potentiate the NO-elicited effect on sinusoidal vessels of corpora cavernosa. ${ }^{9,10}$ The PDE5 enzyme is largely expressed in

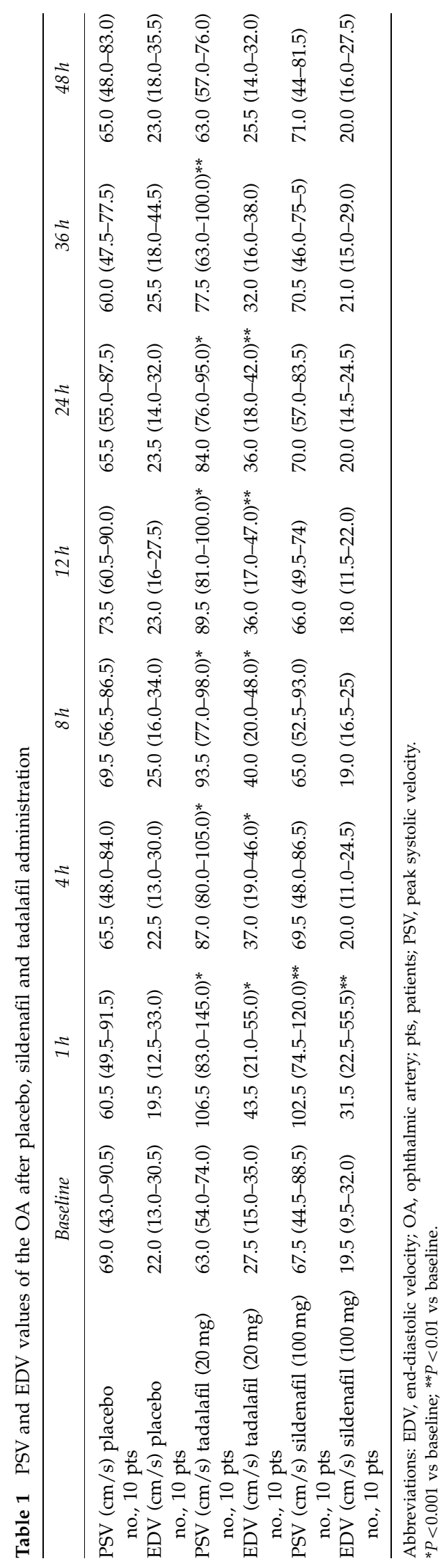




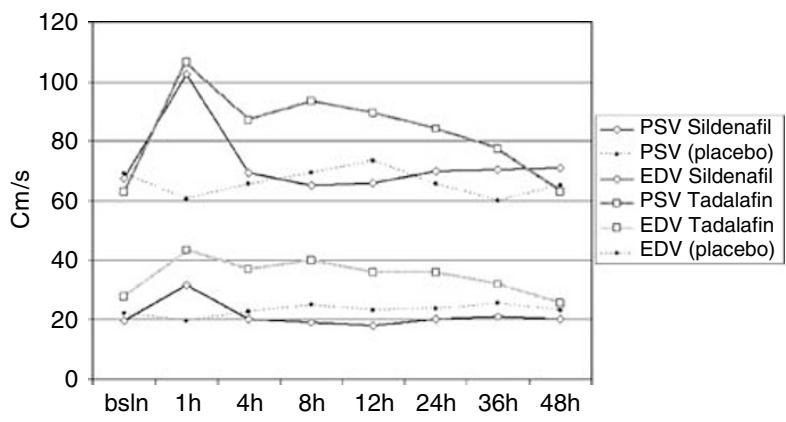

Figure 1 PSV and EDV values in ophthalmic artery after sildenafil $(100 \mathrm{mg})$, tadalafil $(20 \mathrm{mg})$ and placebo uptake. After sildenafil uptake, a significant increase $(P<0.01)$ in OA PSV and EDV was observed only at $60 \mathrm{~min}$ after drug uptake. After tadalafil uptake a significant increase in OA PSV was observed at $1,4,8,12,24(P<0.001)$, and $36 \mathrm{~h}(P<0.01)$. A significant increase in OA EDV values was observed at $1,4,8(P<0.001)$, and $12 \mathrm{~h}, 24 \mathrm{~h}(P<0.01)$ after drug uptake. EDV, end-diastolic velocity; OA, PSV; peak systolic velocity. the corpora cavernosa of the penis, but many other organs express the PDE5 enzyme such as pulmonary and coronary vasculature, sympathetic nervous system, and Purkinje neurons, ${ }^{11-13}$ where its influence is less known. Minor adverse effects of PDE5 inhibitors administration such as headache, flushing, hypotension, dyspepsia, and visual disturbances may be due to this influence and inspired many studies. ${ }^{14-16}$ To the best of our knowledge, the presence of the PDE5 enzyme on the retinal tissue has not been documented and the reported visual side effects of the most studied molecule (sildenafil) has been related to its interaction with PDE6. PDE6 is intensely localized at the rod and cone cells and has an important role in the phototransduction cascade. ${ }^{17-20}$ PDE5 inhibitors show a PDE5 affinity only 10 times greater than PDE6, so some recent studies hypothesized that visual side effects of these drugs may be related to their cross-reactivity with PDE6. ${ }^{21-26}$ a

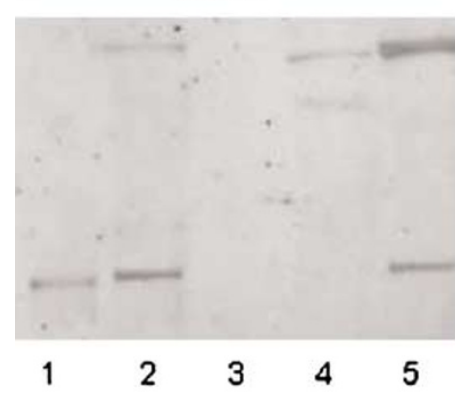

C

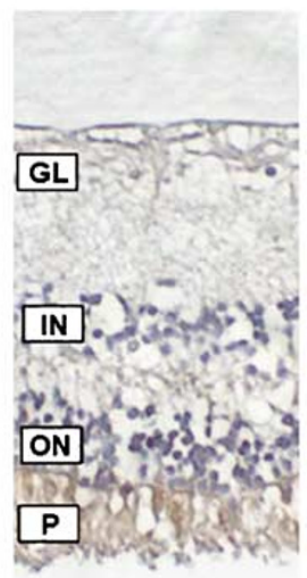

C b PDE5

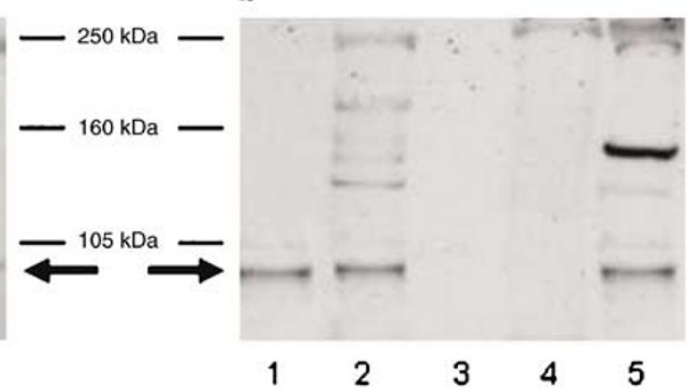

d

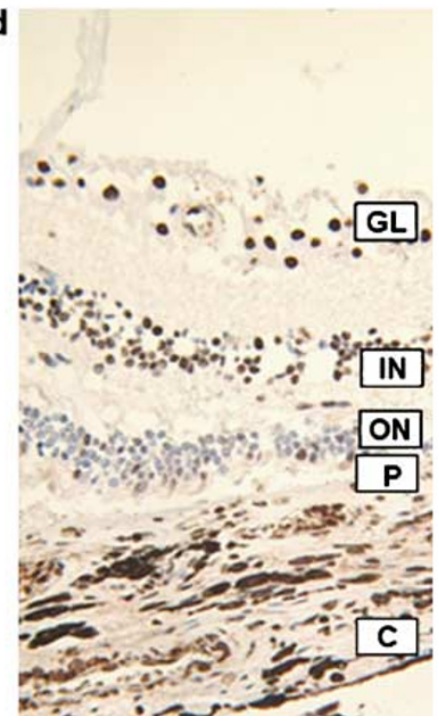

Figure 2 Western blot for both PDE6 and PDE5 ( $a$ and b) demonstrating the presence of the two proteins in human retinal tissues, testis, and corpus cavernosum (1: retina, 2: testis, 3: spermatozoa, 4: skin, 5: corpus cavernosum). The immunohistochemical analysis (c and d) clearly revealed that the PDE6 enzyme is expressed on the photoreceptor layer both on rods and cones. The PDE5 has been localized on endothelial and smooth muscle cells of the vascular wall (retina and choroids vessels), on ganglion cells (III neuron) and bipolar cells (II neuron). C, choroids; P, photoreceptors layer; ON, outer nuclear layer; IN, inner nuclear layer; GL, ganglion cell layer. PDE5, phosphodiesterase type-5; PDE6, phosphodiesterase type-6. 
In addition, few data are available about alterations of ocular blood flow after PDE5 inhibitors administration, and all are about sildenafil. ${ }^{27-32}$ Sildenafil causes a significant increase in blood flow velocity in the ophthalmic artery, a significant dilation of retinal arteries and an increase in choroid and retinal vessels blood flow in healthy subjects. ${ }^{28,30-44}$ This influence may be due to the NO signalling pathway amplification. In fact, blood vessels are innervated by neurons producing $\mathrm{NO}$ that plays a very important role in the local regulation of ocular blood flow. ${ }^{45,46}$ The authors postulated that assuming the existence of PDE5 in the retinal vasculature, these effects may be justified. Recently, Koksal et $a l^{30}$ found that sildenafil causes a significant increase in blood flow of OA, probably as a consequence of PDE5 inhibition on smooth muscle cells, in a timedependent manner. The time course of the vasodilatory effect of sildenafil shows the same pattern as found in the corpus cavernosum and various other human tissue ${ }^{1,11}$ confirming that the mechanism of action is probably the same. Hypothesizing not only a drug-induced but also a class-induced effect on ocular arteries, we compared the blood flow modifications on the OA of a single dose of sildenafil with a single dose of tadalafil. The half-life of sildenafil is about $4 \mathrm{~h}$ (maximum observed plasma concentration within $30-60 \mathrm{~min}$ ) and that of tadalafil is about $48 \mathrm{~h}$ (maximum observed plasma concentration within $30 \mathrm{~min}$ to $6 \mathrm{~h}$ ). We chose to study the OA and not the central retinal artery and the ciliary artery because, for anatomical reasons, the OA is better investigatable (greater and easier to find) and because, from the literature, it seemed that the OA is the most responsive ocular artery after PDE5 inhibitors administration (sildenafil). ${ }^{28,30}$ After the assumption of the two PDE5 inhibitors (sildenafil and tadalafil), we showed an increase in OA blood flow velocity that keep pace with the time metabolization of the two drugs (Figure 1). These findings showed that observed ocular blood flow modifications are not drug-specific but class-specific. Then we investigated the presence of the PDE5 and PDE6 enzyme on human retinal tissues with Western blot and immunohistochemical analysis confirming their presence and giving a map of their distribution. Interestingly, we observed that the PDE5 enzyme has a different distribution with respect to PDE6. In accordance with animal findings, we demonstrate for the first time that the PDE6 enzyme is expressed on human retinal tissues (Western blot) and is located in rod and cone photoreceptors (immunohistochemistry) also in humans where it has a role on visual transduction (low-noise and high-gain signal amplification). The PDE5 enzyme showed a wide expression on retinal and choroidal vessels (Figure 2), confirming the direct influence of PDE5 inhibitors on their dilation. Finally, unexpectedly, we found the presence of the PDE5 enzyme on ganglion (III neuron) and bipolar cell layers (II neuron) (Figure 2). Ganglion and bipolar cell layers act as a filter in the visual signal, giving a first codification of the neural signal. ${ }^{40-43}$ This is of interest because visual side effects after administration of PDE5 inhibitor might now be considered a consequence of a direct effect on the PDE5 enzyme. Therefore, our study has some limitations that deserve comment: first, the relatively small number of subjects; second, we measure CDU readings only in the OA even though measuring of the central retinal artery (CRA) and posterior ciliary arteries (PCA) would yield additional important information.

In conclusion, herein we have demonstrated that (a) tadalafil and sildenafil are able to modify the OA flux in a time-dependent manner; (b) the PDE5 enzyme is expressed on retinal and choroid vasculature (smooth muscle and endothelial cells), on ganglion and bipolar cells; (c) animals human retinal tissues express the PDE6 enzyme in the rod and cone photoreceptors; (d) visual side effects after PDE5 inhibitor administration may be linked not only to their affinity for the PDE6 enzyme, but also to a specific effect on the PDE5 enzyme; (e) the PDE5 enzyme may have a physiologic role on ganglion and bipolar cells that need to be further investigated.

\section{References}

1 Wright PJ. Comparison of phosphodiesterase type 5 (PDE5) inhibitors. Int J Clin Pract 2006; 60: 967-975.

2 Cirino G, Fusco F, Imbimbo C, Mirone V. Pharmacology of erectile dysfunction in man. Pharmacol Ther 2006; 111: 400-423.

3 Burnett AL. Phosphodiesterase 5 mechanisms and therapeutic applications. Am J Cardiol 2005; 96(12B): 29M-31M.

4 Seftel AD. Phosphodiesterase type 5 inhibitors: molecular pharmacology and interactions with other phosphodiesterases. Curr Pharm Des 2005; 11: 4047-4058.

5 Laties A, Sharlip I. Ocular safety in patients using sildenafil citrate therapy for erectile dysfunction. J Sex Med 2006; 3: 12-27.

6 Sponsel WE, Paris G, Sandoval SS, Sanford DK, Harrison JM, Elliott WR et al. Sildenafil and ocular perfusion. $N$ Engl J Med 2000; 342: 1680.

7 Dundar SO, Dundar M, Kocak I, Dayanir Y, Ozkan SB. Effect of sildenafil on ocular haemodynamics. Eye 2001; 15: 507-510.

8 Paris G, Sponsel WE, Sandoval SS, Elliott WR, Trigo Y, Sanford DK et al. Sildenafil increases ocular perfusion. Int Ophthalmol 2001; 23: 355-358.

9 Ignarro LJ, Cirino G, Casini A, Napoli CJ. Nitric oxide as a signaling molecule in the vascular system: an overview. Cardiovasc Pharmacol 1999; 34: 879-886.

10 Goldstein I, Lue TF, Padma-Nathan H, Rosen RC, Steers WD, Wicker PA. Oral Sildenafil in the treatment of erectile dysfunction. N Engl J Med 1998; 338: 1397-1404. 
11 Schwarz ER, Kapur V, Rodriguez J, Rastogi S, Rosanio S. The effects of chronic phosphodiesterase-5 inhibitor use on different organ systems. Int J Impot Res 2007; 12: 381-391.

12 Waldkirch E, Uckert S, Yildirim H, Sohn M, Jonas U, Stief CG et al. Cyclic AMP-specific and cyclic GMP-specific phosphodiesterase isoenzymes in human cavernous arteries - immunohistochemical distribution and functional significance. World J Urol 2005; 23: 405-410.

13 Lin CS. Tissue expression, distribution, and regulation of PDE5. Int J Impot Res 2004; 16: S8-S10.

14 Jackson G. Hemodynamic and exercise effects of phosphodiesterase 5 inhibitors. Am J Cardiol 2005; 96: 32M-36M.

15 Rashid A. The efficacy and safety of PDE5 inhibitors. Clin Cornerstone 2005; 7: 47-56.

16 Kim BJ, Rhee PL, Son HJ. Sildenafil prescribed for erectile dysfunction may induce esophageal symptoms. J Clin Gastroenterol 2005; 39: 643-644.

17 Chabre M, Deterre P. Molecular mechanism of visual transduction. Eur J Biochem 1989; 179: 255-266.

18 Arshavsky VY, Lamb TD, Pugh Jr EN. G proteins and phototransduction. Annu Rev Physiol 2002; 64: 153-187.

19 Yamazaki A, Moskvin O, Yamazaki RK. Phosphorylation by cyclin-dependent protein kinase 5 of the regulatory subunit (Pgamma) of retinal cgmp phosphodiesterase (PDE6): its implications in phototransduction. Adv Exp Med Biol 2002; 514: 131-153.

20 Gonzalez CM, Bervig T, Podlasek C, Huang CF, McKenna KE, McVary KT. Sildenafil causes a dose-and timedependent downregulation of phosphodiesterase type 6 expression in the rat retina. Int J Impot Res 1999; 11(Suppl 1): S9-S14.

21 Marmor MF, Kessler R. Sildenafil (Viagra) and ophthalmology. Surv Ophthalmol 1999; 44: 153-162.

22 Vobig MA, Klotz T, Staak M, Bartz-Schmidt KU, Engelmann U, Walter P. Retinal side effects of sildenafil. Lancet 1999; 353(9150): 375.

23 Vobig MA. Retinal side effects of sildenafil. Lancet 1999; 353(9162): 1442

24 Cote RH. Characteristics of photoreceptor PDE (PDE6): similarities and differences to PDE5. Int J Impot Res 2004; 16(Suppl 1): S28-S33.

25 Jagle H, Jagle C, Serey L, Yu A, Rilk A, Sadowski B et al. Visual short-term effects of Viagra: double-blind study in healthy young subjects. Am J Ophthalmol 2004; 137: 842-849.

26 Stockman A, Sharpe LT, Tufail A, Kell PD, Jeffery G. Viagra slows the visual response to flicker. Curr Biol 2006; 24: R44-R45.

27 Sponsel WE, Paris G, Sandoval SS, Sanford DK, Harrison JM, Elliott WR et al. Sildenafil and ocular perfusion. N Engl J Med 2000; 342: 1680.

28 Dundar SO, Dundar M, Kocak I, Dayanir Y, Ozkan SB. Effect of sildenafil on ocular haemodynamics. Eye 2001; 15: 507-510.
29 Paris G, Sponsel WE, Sandoval SS, Elliott WR, Trigo Y, Sanford DK et al. Sildenafil increases ocular perfusion. Int Ophthalmol 2001; 23: 355-358.

30 Koksal M, Ozdemir H, Kargi S, Yesilli C, Tomac S, Mahmutyazicioglu $\mathrm{K}$ et al. effects of sildenafil on ocular blood flow. Acta Ophthalmol Scand 2005; 83: 355-359.

31 Kurtulan E, Gulcu A, Secil M, Celebi I, Aslan G, Esen AA. Effects of sildenafil on ocular perfusion demonstrated by color Doppler ultrasonography. Int J Impot Res 2004; 16: 244-248.

32 Grunwald JE, Siu KK, Jacob SS, Dupont J. Effect of sildenafil citrate (Viagra) on the ocular circulation. Am J Ophthalmol 2001; 131: 751-755.

33 Muradov H, Boyd KK, Artemyev NO. Analysis of PDE6 function using chimeric PDE5/6 catalytic domains. Vision Res 2006; 46: 860-868.

34 Zhang $X$, Cote RH. cGMP signalling in vertebrate retinal photoreceptor cells. Front Biosci 2005; 10: 1191-1204.

35 Granovsky AE, Artemyev NO. Partial reconstitution of photoreceptor cGMP phosphodiesterase characteristics in cGMP phosphodiesterase-5. J Biol Chem 2001; 276: 21698-21703.

36 Stacey P, Rulten S, Dapling A, Phillips SC. Molecular cloning and expression of human cGMPbinding cGMP-specific phosphodiesterase (PDE5). Biochem Biophys Res Commun 1998; 247: 249-254.

37 Metelitsina TI, Grunwald JE, DuPont JC, Ying GS. Effect of Viagra on the foveolar choroidal circulation of AMD patients. Exp Eye Res 2005; 81: 159-164.

38 Vatansever HS, Kayikciouglu O, Gumus B. Histopathologic effect of chronic use of sildenafil citrate on the choroids \& retina in male rats. Indian J Med Res 2003; 117: 211-215.

39 McCulley TJ, Luu JK, Marmor MF, Feuer WJ. Effects of sildenafil citrate (Viagra) on choroidal congestion. Ophthalmologica 2002; 216: 455-458.

40 Neves G, Lagnado L. The retina. Curr Biol 1999; 9: R674-R677.

41 Trexler EB, Li W, Massey SC. Simultaneous contribution of two rod pathways to All amacrine and cone bipolar cell light responses. J Neurophysiol 2005; 93: 1476-1485.

42 Dacey DM, Liao HW, Peterson BB, Robinson FR, Smith VC, Pokorny $\mathrm{J}$ et al. Melanopsin-expressing ganglion cells in primate retina signal colour and irradiance and project to the LGN. Nature 2005; 17: 749-754.

43 Nirenberg S, Carcieri SM, Jacobs AL, Lathman PE. Retinal ganglion cells act largely as independent encoders. Nature 2001; 411: 698-701.

44 Pache M, Meyer P, Prunte C, Orgul S, Nuttli I, Flammer J. Sildenafil induces retinal vasodilation in healthy subjects. $\mathrm{Br}$ J Ophthalmol 2002; 86: 156-158.

45 Toda N, Nakanishi-Toda M. Nitric oxide: Ocular blood flow, glaucoma, and diabetic retinopathy. Prog Retin Eye Res 2007; 26: 205-238.

46 Goldstein IM, Ostwald P, Roth S. Nitric oxide: a review of its role in retinal function and disease. Vision Res 1996; 36: 2979-2994. 